\title{
Aguerridos, esforzados y porteños: el imaginario wanderino de Valparaíso por medio de la revista Estadio*
}

Brave, Hardworking and Porteños: The Wanderino

Imaginary of Valparaiso Through Estadio Magazine

Aguerridos, esforçados e portenhos: o imaginário

"wanderino" de Valparaíso através de Revista Estadio

\author{
Carlos Daniel Vergara Constela** \\ Sebastián Enrique Ponce Olmos ${ }^{* * *}$ \\ Eric Antonio Valenzuela Martínez $z^{* \star \star}$
}

Recibido: 13 de marzo de 2015

Aprobado: 29 de septiembre de 2015

Doi: dx.doi.org/10.12804/territ34.2016.06

Para citar este artículo

Vergara C., C. D., Ponce O., S. E., \& Valenzuela M., E. A. (2016). Aguerridos, esforzados y porteños: el imaginario wanderino de Valparaíso por medio de la Revista Estadio, Territorios, 34, 137-160. Doi: dx.doi. org/10.12804/territ34.2016.06 
Palabras clave

Imaginarios urbanos, estilo de juego, Revista Estadio, Santiago Wanderers de Valparaiso.

Keywords

Urban Imaginaries, play's style, Estadio Magazine, Santiago Wanderers of Valparaiso

Palavras-chave

Imaginários urbanos, Estilo de Jogo, Revista Estadio, Santiago Wanderers de Valparaíso.

tersitarias 34

\section{RESUMEN}

Bajo la mirada de los imaginarios urbanos, se revisa la influencia que tuvo la extinta Revista Estadio en el imaginario wanderino de Valparaíso. Para esto se repasa la relación entre imaginarios urbanos y fútbol, la posición hegemónica de Estadio en su época de publicación, y aspectos ligados a la época fundacional de Santiago Wanderers, símbolo de Valparaíso. Luego, se analiza la construcción del estilo de juego y la figura del ídolo, ambas representaciones mediadas por la labor de Estadio, las cuales otorgan carácter, se actualizan y persisten hasta esta época en el imaginario wanderino de Valparaíso.

\section{ABSTRACT}

Through the concept of urban imaginaries, the influence that the defunct Magazine Estadio left in the wanderino imaginary of Valparaiso is explored. In order to do this the relationship between urban imaginaries and football, the Estadio hegemonic position in his time of publication, and aspects linked to the founding era of Santiago Wanderers, symbol of Valparaiso are reviewed. Then this article pretends to analyze the construction of the style of play and the figure of the idol, both represented through the work of Estadio. These representations give character, are updated and persist until our time in the wanderino imaginary of Valparaiso.

\section{RESUMO}

Sob o olhar dos imaginários urbanos se revisa a influência que teve a extinta Revista Estadio no imaginário "wanderino" de Valparaíso. Para isto repassa-se a relação entre imaginários urbanos e futebol, a posição hegemónica Estadio em sua época de publicação, e aspetos ligados à época fundacional de Santiago Wanderers, símbolo de Valparaíso. Após, analisa-se a construção do estilo de jogo e a figura do ídolo, ambas as representações mediadas pelo trabalho de Estadio, as quais outorgam carácter, se atualizam e persistem até a nossa época no imaginário "wanderino" de Valparaíso. 


\section{Introducción}

En Valparaiso, los vendedores usan la insignia verde para conquistar a sus clientes $y$ los automovilistas para sacarse los partes. La palabra Wanderers va siempre acompañada de una sonrisa, porque Wanderers es Valparaiso y Valparaiso es Wanderers

(Revista Estadio, 1949, 294, 6)

La ciudad de Valparaíso, la cual se erigió como uno de los puertos más importantes de América Latina durante fines del siglo XIX e inicios del siglo Xx (Trivelli \& Nishimura, 2010), fue expandiéndose como ciudad por medio de la migración interna, principalmente de peonaje rural y al peonaje urbano desplazado de la industria minera (predominantemente salitrera) del norte de Chile, y de inmigrantes europeos (principalmente ingleses, alemanes, españoles e italianos) que llegaban a controlar el auge portuario y comercial, o lisa y llanamente iban a buscar un espacio para trabajar.

Desde fines del siglo XIX la ciudad fue construida discursivamente mediante un mito fundacional: Valparaíso era (o es) igual a aliamapu o tierra quemada. Aquello posibilitó la significación del espacio de la ciudad como un lugar inhóspito para la vida, básicamente entendido como un lugar "sufrido"(Calderón \& Schlotfeldt, 2001). Desde entonces, Valparaíso, como un lugar sufrido, se ha erigido como una de las retóricas locales más potentes y persistentes a lo largo del tiempo.

Ahora bien, el fútbol, como espacio donde apreciar la dramatización de valores sociales (Archetti, 2001), es un terreno fértil para el inacabable estudio de la identidad. Debido al proceso de apropiación cultural del fútbol en Chile, como ningún otro deporte, es evidente su utilidad para cartografiar las tramas sociales en distintos espacios de la ciudad desde un sentido imaginado y vivido de su construcción.

Los imaginarios urbanos son entendidos como redes o tramas de significados específicas, reconocidas socialmente, que le otorgan cualidades a la ciudad, sus lugares y habitantes (Lindón, 2007a). Bajo este precepto se caracteriza al club de fútbol profesional Santiago Wanderers como elemento de la cultura urbana porteña y símbolo de Valparaíso, que permite identificar imaginarios presentes en el espacio simbólico de la ciudad. Por medio de una estrategia metodológica cualitativa, se indaga en la articulación de uno de estos constructos sociales: el imaginario wanderino de Valparaíso por medio del análisis realizado sobre Revista Estadio y complementado con otras fuentes referidas al club porteño (videográficas, bibliográficas y orales). Para esto, primero se da cuenta de la relación entre imaginarios urbanos y fútbol. Luego, se revisa la época de fundación de Santiago Wanderers y el nacimiento del fútbol, asociado con Valparaíso y Chile. Posteriormente, $\mathrm{y}$ justamente en paralelo al proceso de profesionalización del fútbol, se presenta el rol y las características de revista Estadio, dada su posición hegemónica como medio de comunicación difusor del deporte a nivel nacional durante el periodo "desarrollista" (Santa Cruz \& Santa Cruz,
Universidad de Valparaíso. Correo electrónico: sebaponce87@gmail.com

**** Sociólogo por la Universidad de Valparaíso, Chile. Núcleo de Estudios en Sociología del Fútbol, Universidad de Valparaíso. Correo electrónico: ericvalenzuelam@hotmail.com

territarias 34

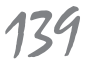


2005). Debido al accionar de Estadio, el imaginario wanderino se actualiza y colma representaciones encubiertas en analogías, metáforas, arquetipos y estereotipos sobre lo "porteño" (gentilicio para los habitantes de Valparaíso), y sobre lo viñamarino (gentilicio para los habitantes de Viña del Mar), la otredad que sirve como espejo a Valparaíso. En este punto del trabajo se visualiza cómo la construcción de un estilo de juego y la función representativa que cae sobre los ídolos erigen representaciones sólidas que, hasta el día de hoy, circundan en el plano evocativo y material de la cultura urbana y futbolística de Valparaíso, a pesar de las transformaciones urbanas que ha sufrido la ciudad y la reestructuración del campo del fútbol global, latinoamericano y chileno.

En definitiva, el carácter de símbolo de Santiago Wanderers permite apreciar cuáles son las matrices de sentido y esquemas de significación imperantes en los habitantes de la ciudad y de quienes han mirado, estudiado u observado Valparaíso; cómo se piensan, cómo se significa su experiencia urbana y cómo es pensado el puerto y su otro, por medio de un club de fútbol.

\section{Los imaginarios urbanos del fútbol}

Los imaginarios urbanos constituyen un constructo teórico que ha sido llenado gracias al aporte de distintas disciplinas. Es un concepto que necesariamente adquiere naturaleza transdisciplinaria. Sus orígenes pueden remitirse tanto al constructivismo social de Berger \& Luckmann (2000), como al constructivismo geográfico de David Ley (1978). En este sentido, se debe establecer que los territorios se construyen socialmente, diferenciándose y distinguiéndose de otros (Bailly, 1989; Ley, 1978; Lindón, 2007a). Desde esta perspectiva, los territorios se forjan socialmente mediante el diálogo inacabable entre las estructuras objetivas de un espacio determinado y las estructuras cognitivas de los sujetos que habitan en dicho espacio.

El universo simbólico (ideologías territoriales, valores patrimoniales, memoria colectiva, sentimientos de identidad) de las estructuras cognitivas del sujeto social encuentra un campo de referencias sólidas en las estructuras objetivas del espacio geográfico. Estos aportan argumentos de identidad, hitos innumerables, y capaces de restablecer la memoria colectiva para las sociedades que los producen. En el centro de este fuego cruzado de interferencias ideales y materiales, lejos de expresar rutinas invariables, las prácticas tranquilas de lo cotidiano demuestran, en forma permanente, un asombroso espíritu de invención; son ellas las que producen, sin descanso, el espacio geográfico y sus territorios (Di Meo, 1999).

El estudio de la construcción social de los territorios ha sido relevado en América Latina desde un par de décadas atrás. El aporte invaluable de autores como Armando Silva $(1986,2006)$ o Néstor García Canclini (1997) han posicionado el constructo teórico de los imaginarios urbanos como una herramienta conceptual, idónea para el estudio de las culturas urbanas. 
Estos - los imaginarios urbanos - han adoptado un carácter procesual: son entendidos como matrices de sentido socialmente estructuradas (Márquez, 2007); complementos de sentido a las representaciones (Hiernaux, 2007); o bien, tramas de significado socialmente compartidas enmarcados contextualmente (Lindón, 2007a). Los imaginarios urbanos operan bajo la cualificación de determinados lugares, atribuyéndole características y significados realizados por diferentes grupos sociales. Precisamente, estos se componen de narrativas, representaciones e imágenes (Hiernaux, 2007; Lindón, 2007b) que articulan una relación compleja entre las memorias, los significados y los deseos de los habitantes de un espacio urbano dado (Lindón, 2006).

La representación, en su acepción más primordial, da cuenta de un acto cognitivo capaz de producir signos o símbolos capaces de volver a presentar algo que no se encuentra en el presente, siendo restituido en una re-presentación. En este sentido, volver a presentar es suplir y actualizar la ausencia de un otro. De acuerdo con Victoriano \& Darrigrandi (2009), las representaciones constituyen la estructura de comprensión por la cual sujetos ubicados en un espacio social determinado aprehenden y comprenden $s u$ mundo, por lo que estos portan significados materializados en diferentes lenguajes (escritos, corporales, visuales, auditivos, etc.). Al respecto, Lindon y Hiernaux (2007) sostienen que existe una confusión en el uso de conceptos emparentados, tales como imagen, ima- ginación, imaginarios, símbolo, signos y representaciones. Sobre esto aportan una diferenciación semántica, señalando que:

La representación es una forma de traducir en una imagen mental, una realidad material no presente o bien una concepción. En cambio, el imaginario es más que eso: es una superación de la simple reproducción generada por la representación, hacia la imagen creadora. El imaginario es entonces un proceso dinámico que otorga sentido a la simple representación mental y que guía la acción. La imaginación es una forma de acceso a la realidad, el proceso por el cual se realiza la representación-transfiguración simbólica [...] mientras que el imaginario es la capacidad, la fuerza de esa transformación (p. 158).

Al respecto, Alabarces (2007), quien ha estudiado la producción de representaciones e imaginarios en torno a la relación entre fútbol y nación en la Argentina, desde el aparataje conceptual de Bronislaw Backzo, sostiene que en la noción de representación, la mediación de distintos agentes productores de estas es ineludible. De acuerdo con esto, se afirma lo siguiente:

A lo largo de la historia, las sociedades se entregan a una invención permanente de sus representaciones globales, otras tantas ideas-imágenes a través de las cuales se dan una identidad, perciben sus divisiones, legitiman su poder o elaboran modelos formadores para sus ciudadanos, tales como "el valiente guerrero", "el buen ciudadano", "el militante comprometido", etc. Estas 
representaciones de la realidad social (y no simples reflejos de esta), inventadas y elaboradas con materiales tomados del caudal simbólico, tienen una realidad específica que reside en su misma existencia, en su impacto variable sobre las mentalidades y los comportamientos colectivos, en las múltiples funciones que ejercen la vida social (Backzo, 1991, p. 8).

A su vez, y a modo de no generar malos entendidos o visiones parcialmente distorsionadas sobre la concepción de imaginarios urbanos, también cabe realizar una sucinta diferenciación respecto de la noción de imagen urbana. De acuerdo con Fuentes (2000), las imágenes urbanas son representaciones mentales globales del medio urbano, donde elementos selectos son puestos en conjunción para condensar y sintetizar la imagen de una ciudad determinada. Al respecto, y tomando en consideración lo manifestado por Fuentes, la antropóloga argentina Mónica Lacarrieu (2007) indica que las imágenes urbanas son productos de campos de lucha simbólica sobre lo que se pretende representar de una determinada ciudad. Sobre esto profundiza y detalla:

Son construcciones parciales, simplificadas y distorsionadas. Las imágenes no son la realidad sino la representación de esa realidad que se constituye a partir del resumen de evaluaciones, concepciones del mundo, preferencias, homogeneizando una idea de ciudad. Así, toda imagen urbana es un cúmulo de estereotipos, de cuya sumatoria emerge una imagen estereotipada de la ciudad en cuestión y, por ello, es una falacia: no es mentira, pero no es absolutamente cierta [...], las imágenes urbanas acaban constituyéndose en la materia prima de los discursos, los valores y las prácticas sociales. Hay imágenes que son legitimadas y se tornan hegemónicas en las disputas sociales. Suelen aspirar a definir proyectos urbanos que pretenden imponerse a la ciudadanía, conformando y transmitiendo valores y comportamientos desde los cuales se decide qué formas de apropiación de los espacios se autorizan y qué rasgos culturales deben asumirse (p. 51).

Si bien, la tendencia a homologar imagen e imaginario da cuenta de prenociones bastante arraigadas, la diferencia sustancial entre estos conceptos radica en su orden y definición. Mientras el imaginario urbano da cuenta de cómo los habitantes de una ciudad representan, significan y dotan de sentido el acto de habitar y su experiencia urbana (Hiernaux, 2007; Lindón, 2007a y 2007b; Márquez, 2007; Silva, 2006), la imagen urbana generalmente es resultado de construcciones oficiales "producto de una acción intencional de recorte y selección”, que busca mostrar - en clave normativa-, cómo debe ser vivida la ciudad, qué se permite, qué se tolera, qué se valora, qué se debe memorar y qué no, siendo totalmente de carácter prescriptiva (Lacarrieu, 2007). Por lo tanto, las imágenes urbanas, como unidades de análisis y concepto construido por diferentes cientistas sociales, tienden a ubicarse como un componente y una dimensión de la cual los imaginarios deben nutrirse y deben consi- 
derar como acción fundamental la decodificación de estas.

Los imaginarios, entendidos como matrices de sentido, tramas de significado o guías actuantes, necesitan del símbolo para salir de su condición de virtualidad (Vergara, 2001). Estos, los símbolos, tienen la capacidad de apelar al plano emotivo, condensando prácticas y representaciones, así como unificando significados dispares e incluso polarizando sentidos (Melgar, 2001). De esta manera, el símbolo debe ser comprendido como un elemento implicativo puesto que vincula, relaciona, une y visibiliza. Debido a esta condición, Alicia Lindón (2007a) ha señalado que "El imaginario urbano ha ido uniendo simbólicamente prácticas, locus, objetos y sujetos de ciertas formas, que permiten contar historias, atribuir valores y significados, imaginar futuros y reconstruir pasados" (p. 39).

En total relación con lo anterior, y sin provenir del mundo de los estudios urbanos, Eduardo Santa Cruz (1991, 1996) ha señalado que las instituciones deportivas chilenas - precisamente futbolísticas - a lo largo de su historia se han instituido como símbolos. Por ejemplo, Santiago Wanderers, club fundado en 1892 es catalogado como uno de los símbolos más importantes de Valparaíso, el territorio que acoge y al cual este club representa. En este sentido, el fútbol apropiado culturalmente por los sectores medios y populares se transformó rápidamente en su época de gestación: desde la función propia que los sectores ingleses aristocráticos inmigrantes que llegaron al país a fines del siglo XIX le atribuían, en tanto actividad recreativa, cultivo del cuerpo y excusa para realizar acuerdos de otra índole. La apropiación cultural por parte de los sectores medios y populares criollos dota a este deporte de un componente simbólico, donde, por ejemplo, la forma de cómo desempeñarse en la cancha y el resultado del partido adquieren relevancia social (Alabarces, 2000; Guerrero, 2006; Santa Cruz, 1996). Por lo tanto, el fútbol, en su faceta simbólica, tiende a confirmar o compensar subordinaciones, frustraciones e incluso resentimientos sociales derivados de los grupos sociales representados por los clubes.

La segunda mitad del siglo xx es clave para comprender la relación entre imaginarios y fútbol. Por un lado, se produjo un proceso de profesionalización del fútbol a nivel latinoamericano, y, por otro, la industria cultural chilena se encontraba en pleno crecimiento. Es en este marco, cuando emergen con inusitada densidad representaciones como los estilos de juego y también sobre los ídolos. El antropólogo argentino Eduardo Archetti (2001, 2008), quien ha estudiado la relación entre imaginarios y fútbol, ha relevado la importancia social y cultural de los estilos de juego practicados por diferentes clubes. Estos son entendidos como una práctica simbólica donde se expresan estereotipos representativos de determinadas escalas territoriales (barrios, ciudades, regiones y/o países). El estilo de juego es ante todo una forma deseada de jugar, porque de esa manera se logra representar de manera fiel a grupos sociales que desearían jugar de territarias 34 143 
${ }^{1}$ Para profundizar en las revistas deportivas del espectro nacional, se sugiere revisar a Santa Cruz (2012).

\section{territarias 34} 144 la misma manera si estuviesen dentro del campo de juego.

Por su parte, los ídolos también poseen una función representativa. En este caso son comprendidos como arquetipos, puesto que resaltan modelos de comportamiento a seguir (Valenzuela \& Vergara, 2014). Estos son representados como un adalid, es decir, una suerte de modelo de vida que en el campo de juego defenderá el orgullo colectivo de un determinado grupo social, sin darle total relevancia al resultado final, sino a los medios utilizados (Santa Cruz \& Santa Cruz, 2005). Por lo tanto, los ídolos y los estilos de juego tienen la potencialidad de cristalizar una identidad y sedimentar la construcción de un territorio (Dávila \& Londoño, 2003). Dicho de otra manera, por medio de un club de fútbol - erigido como un símbolo, dado su condición histórica y posicionamiento en el universo simbólico de un territorio-, los habitantes logran significar, ser representados y otorgar sentidos al acto de habitar.

\section{La posición de revista Estadio en el fútbol chileno}

La revista Estadio nació en el marco del surgimiento de la industria cultural moderna chilena. Esta se afianzó mediante la divulgación de revistas que estaban destinadas a satisfacer distintos públicos: infantil, cine, espectáculos, política y deporte (Ossandón \& Santa Cruz, 2001). Estadio fue fundada en Santiago durante 1941 y editada por la empresa ZIG-ZAG. Si bien, no fue la primera publicación deportiva en el país ${ }^{1}$, siguiendo a Eduardo Santa Cruz y Luis Santa Cruz (2005), esta revista es considerada como una de las expresiones más elevadas de la práctica periodística en Chile. Se publicaron 2048 ediciones durante el periodo comprendido entre los años 1941 y 1982. Además, la revista tenía difusión nacional, he ahí uno de los puntos que detonan su relevancia en la época.

Uno de sus mayores legados tiene relación con la consolidación total del periodismo deportivo en Chile, posicionando precisamente a los y las periodistas como los narradores por excelencia de las prácticas y eventos deportivos. Si bien, Estadio no fue la primera revista deportiva a nivel nacional, sí es catalogada como la más importante debido a su formato, temporalidad, secciones y estilo periodístico.

La prensa deportiva, y en especial la revista Estadio, se colocaba en una perspectiva orientadora y formativa de un público específico, en el sentido, si se quiere, habermasiano del término, es decir, informando y con capacidad de tomar la distancia necesaria para el juicio crítico, fuera del aplauso y del rechazo. Asimismo, se constituía en un polo permanente de difusión del rol del deporte (Santa Cruz \& Santa Cruz, 2005).

Por otro lado, Estadio cumplió un rol relevante en el periodo desarrollista chileno, comprendido temporalmente entre los gobiernos de Frente Popular y la Unidad Popular. En esta época la revista apoyó y difundió sistemáticamente la idea que señalaba que el deporte se constituía como un medio efectivo para lograr la superación moral del pueblo, sosteniendo reite- 
radamente que la actividad física colectiva funcionaba como un mecanismo para "mejorar la raza" (Santa Cruz \& Santa Cruz, 2005). Precisamente, sobre esto Santa Cruz (2003) ha mencionado lo siguiente:

Dicha publicación fue un permanente difusor y propagandista del rol social y cultural que jugaba el fútbol y el deporte en el proceso de desarrollo del país, pero en ningún caso fue una excepción. Por el contrario, más bien recogía y sistematizaba un sentido común masivamente compartido al respecto (p. 203).

La importancia de Estadio radica en que esta revista se constituyó como el principal medio difusor de los deportes a nivel nacional, siendo el fútbol el que más cobertura recibió. En este sentido, la cobertura de los equipos de "regiones", mediante enviados especiales, contribuyó a la creación de representaciones sobre los equipos y sobre los públicos de los territorios que cobijaban a estos mismos equipos, propiciando el desarrollo y reproducción de estereotipos y arquetipos locales emanados desde el centro del país con recepción a nivel de las principales ciudades de las regiones de Chile.

En términos metodológicos, la técnica de producción de datos utilizada correspondió a la investigación documental. Se utiliza esta técnica en cuanto testimonio escrito de una época, rescatando el carácter de equivalencia que los documentos tendrían en cuanto estarían respondiendo a un uso cultural ligado a una época determinada (Valles, 2000). La introduc- ción en los documentos es en sí una técnica documental en la cual se hace una lectura de textos, comprendiéndolos como elementos que poseen y preservan significados Es más, como sugiere Valles (2000), estos textos se pueden observar de la misma forma, o con equivalente intensidad con la que se observan diferentes ritos, manifestaciones, partidos de fútbol u otros acontecimientos. En este caso, la lectura es una mezcla de entrevista/observación y puede desarrollarse como cualquiera de ellas. La riqueza y relevancia de la técnica documental corresponde a que los documentos se articulan como registros que se pueden leer, observar, etc., y se refieren a algún aspecto de la sociedad, realizados con la intencionalidad de dejar registro de un determinado contexto social (Valles, 2000). Estos registros pueden llegar a representar la realidad tal como fue concebida en determinado momento histórico, logrando la capacidad de absorber y detallar una realidad que remite al detalle, al momento de la cotidianidad e, incluso, lo trasciende en su forma típica (Longo, 2006).

Concretamente, se revisaron aproximadamente trescientos números de revista Estadio comprendidos entre 1942 y 1976 , que hacían alusión a Santiago Wanderers o a partidos disputados contra Everton de Viña del Mar (clásicos porteños). Específicamente, el ojo investigativo estuvo sobre las notas que analizaban partidos del campeonato nacional de fútbol, reportajes sobre la historia de los clubes y entrevistas a jugadores profesionales. Los registros periodísticos de Estadio fueron comple- 
${ }^{2}$ Cabe recordar la relevancia que tenía Valparaíso en la época de la fundación de Santiago Wanderers. Julio Pinto (1987) considera a esta ciudad como la capital financiera de Chile. Por otro lado, se debe destacar la importancia que tuvieron los intercities en la bistoria del fútbol chileno. Estos eran partidos entre protoselecciones de estas ciudades, lo que no solo comenzaba a configurar una rivalidad netamente deportiva, sino que ponía en el tapete una disputa simbólica entre las capitales del pais; Valparaiso la capital económica por ese entonces y Santiago, la capital administrativa de Chile (Marin, 1995; Santa Cruz, 1991 y 1996).

${ }^{3}$ A modo de establecer un "lugar de la memoria", aproximadamente, hace tres años la municipalidad de Valparaiso colocó una bandera y una placa en rememoración del espacio donde Santiago Wanderers disputó sus primeros partidos como club.

${ }^{4}$ Para un conocimiento cabal y sistemático de los orígenes, desarrollo y conflictos de la Football Association of Chile, sus posteriores transformaciones.

territarios 34 mentados con material audiovisual alusivo al club de Valparaíso. Los datos recopilados, cargados de metáforas, analogías y homologías referentes a lo que significa jugar en Santiago Wanderers, a postulaciones identitarias sobre cómo son los y las porteñas en comparación a Viña del Mary a Everton, fueron sometidos a un análisis de contenido cualitativo, donde se extrajeron códigos, subcategorías y metacategorías articuladas con base al marco conceptual de los imaginarios urbanos.

\section{Fútbol y ciudad: el imaginario wanderino de Valparaíso}

En medio de la vorágine iniciática del deporte en Valparaíso, Santiago Wanderers fue fundado en 1892 en Valparaíso por jóvenes de procedencia criolla, en uno de los cerros aledaños a la zona portuaria de la ciudad. De acuerdo con los registros periodísticos de Edgardo Marín (1995), el estudio historiográfico de Eduardo Santa Cruz (1991) y el ya añoso anecdotario biográfico de Manuel Díaz (1952), el origen mítico de la institución da cuenta de un proyecto deportivo de jóvenes y niños que pretendían disputar la hegemonía inglesa en la ciudad bajo la construcción de un argumento que valora lo nacional (lo chileno) sobre lo extranjero (lo inglés) ${ }^{2}$. De hecho, el mito cuenta que el nombre "Santiago" se debe a dos motivos: la existencia previa de un Valparaíso Wanderers (equipo de raigambre inglesa) y la necesidad de distinguirse nominalmente en algo que representara lo chileno, en este caso, el nombre de la capital. Los primeros pasos en el mundo deportivo fueron dados en la cancha El Empedrado, ubicada en el denominado Barrio Puerto, a un costado de la actual Plaza Wheelright, el ascensor Artillería y el inmueble de la Aduana ${ }^{3}$.

En junio de 1895, un aviso del periodista Robert Reid en del periódico The Chilean Times convocaba a representantes de clubes de la ciudad a formar una asociación de fútbol para Chile. A la reunión asistieron más de cincuenta personas, entre ellas, representantes del Victoria Rangers, Valparaíso F.C., Chilian F.C., y Mackay and Sutherland Athletic, quienes forjaron la Football Association of Chile. Esta legitimó su oficialidad mediante la afiliación a la CONMEBOL en 1915 (Marín, 1995) ${ }^{4}$.

De este modo, por medio de la creación de competiciones, se fue desarrollando y ampliando la práctica deportiva en Valparaíso y en las principales ciudades de Chile. Dado el carácter británico de la Football Association of Chile, en 1897 surge una federación paralela presidida por Arturo Fernández Vial: la National Football Association. En esta participaron clubes de raigambre nacional como Liceo Wanderers, Chile-Brasil, La Cruz, Cordillera y Santiago Wanderers, entre otros (Díaz, 1952). Este último - Santiago Wanderers- pasó a formar parte de la Football Association of Chile desde 1899. La dimensión idiomática es importante de tomar en cuenta porque la difusión del deporte en Valparaíso se hizo a por medio del periódico de habla inglesa The Chilean Times, por lo tanto, el fútbol era hablado, pactado y normado en inglés. 
La castellanización del fútbol, institucionalizada en 1903, es propulsada por Santiago Wanderers.

En Valparaíso, Santiago Wanderers ya es institución señera y el 24 de abril, en el consejo de la Football Association of Chile celebrado en el local de la Primera Compañía de Bomberos, hace oír su voz y consigue que el organismo resuelva que, en lo sucesivo, las publicaciones, acuerdos y actas se hagan en castellano, y que sus inserciones se publiquen en los diarios y periódicos chilenos (Marín, 1995, p. 37).

La Football Association of Chile tiene a la Liga de Valparaíso como su competición más relevante durante las primeras décadas del siglo $\mathrm{xx}^{5}$. No obstante, la fundación en 1903 de la Asociación de Fútbol de Santiago comenzó a disputar la hegemonía nacional con Valparaíso, hasta que en 1929, bajo mandato el presidencial de Carlos Ibáñez del Campo, se crea la Federación de Fútbol de Chile, la cual tiene sede en la capital nacional y posee jurisprudencia sobre todo el territorio. Esto llevaría a que la Football Association of Chile - ya por esos años llamada Liga Valparaíso- solo tuviese representatividad regional (Santa Cruz, 1995).

La participación de Wanderers en las competiciones amateurs de Valparaíso fue erigiéndolo como un club popular, gracias a sus buenos resultados deportivos y la asociación que se hacía del club con los sectores medios y populares de la ciudad. Debido a esto, fue invitado en 1937 a jugar en la
Asociación Central de Fútbol Profesional (ACF), pero no obtuvo mayores éxitos. En 1940 fundó, junto a Everton de Viña del Mar, Administración Puerto, Club Deportivo Las Zorras, La Cruz y otros clubes, la Asociación Porteña de Fútbol Profesional. En ella obtuvo dos campeonatos (19411942), sin embargo, su desvinculación (así como también la de Everton de Viña del Mar) relegó a esta asociación al amateurismo. De esta manera, Wanderers volvió a la ACF (actual ANFP) para comenzar a construir su historia en un escenario profesional de carácter nacional. He aquí donde Estadio, en el marco del inicio de la cultura de masas en Chile, cobra extraordinaria relevancia en la construcción de este imaginario.

Revista Estadio, entendida como medio de comunicación hegemónico del ámbito deportivo del país durante el periodo desarrollista, relevó con insistencia representaciones sobre Valparaíso y sus habitantes. El foco de Estadio sobre Santiago Wanderers estuvo puesto en tres ámbitos: en la forma de desempeñar un estilo de juego particular, en la fisonomía y características físicas y/o corporales de algunos de los jugadores más representativos, y en la relación del club con Valparaíso. En muchas ocasiones, estos elementos aparecen entremezclados dentro del discurso de Estadio, así como Viña del Mar y Everton aparecen como una suerte de espejo constante. Obviamente, este medio plantea asociaciones, metáforas y/o analogías entre unas y otras. En este caso, y sin la intención de quitarle densidad analítica a la materia que de esta investigación, la idea es presentar la cons-
Cabe destacar que Santiago Wanderers obtuvo esta liga en 1907, 1909, 1913, 1915, 1917, 1919, 1921, 1933, 1934, 1935.

territarias 34 147 
trucción de los ídolos porteños y el estilo de juego wanderino por separado, con el fin de poder ilustrar de mejor manera cada representación.

\section{4. Ídolos wanderinos: representantes arquetípicos del habitante porteño}

En las innumerables crónicas de Estadio, el estilo grupal es encarnado en un jugador con características emblemáticas, adquiriendo un carácter icónico y arquetípico. El ídolo, esa suerte de adalid que representa "de la mejor manera posible" a los aficionados e integrantes de un club en particular (Santa Cruz, 1996), es construido como una bandera, es decir, como un emblema que reproduce fielmente las características de dicho club. En el caso Santiago Wanderers, Estadio indica que los "caturros" son luchadores, empedernidos y vehementes. Estas características están contenidas en determinados jugadores, debido a lo cual se produce una suerte de simbiosis entre el ídolo y el estilo. Jesús Picó fue un ejemplo de aquello:

En todos los equipos hay jugadores simbólicos. Como si fuesen insignia. Dijérase que no se les puede imaginar con otros colores. Imposible. Están encasillados para siempre con un uniforme. Es lo que ocurre con Wanderers y Jesús Picó. Una bandera preñada de tradición y un jugador que es su mejor exponente $[\ldots]$ Es que en la personalidad deportiva del insider porteño parece reflejarse mucho de las características imponderables del club. Joven, temperamento tumultoso, luchador, empedernido, amor propio, que a veces suele hacerlo vehemente. Eso es Wanderers. Así es Picó (Revista Estadio, 1958, 815, pp. 14-15).

Para continuar, es pertinente detenerse precisamente en uno de los jugadores más emblemáticos de la historia del club, si no el más emblemático de la institución porteña: el arquero Juan Olivares, quien representó por más de diez años a los wanderinos e incluso jugó dos copas del mundo por la selección chilena (1966 y 1974). Nacido en Viña del Mar y proveniente del barrio obrero de Santa Inés, a él se le incorporan una serie de características físicas y disposiciones corporales que lo asimilan al estereotipo del habitante porteño: la piel morena, la estatura baja y el trabajo portuario. Sin embargo, Olivares es viñamarino pero su fisonomía en ningún caso representa al habitante característico e idealizado de la ciudad-balneario.

\footnotetext{
$\mathrm{Al}$ respecto, uno no deja de ser curioso con lo que ocurre con los arqueros de la costa. Uno, Adison Aguilar, rubio, elegante y muy alto como la propia Viña del Mar. El otro, Juan Olivares, tez morena, pelo negro y jockey inclinado como el muchacho inconfundible de cerro y de la dársena. Y ambos relativamente menudos, pero sumamente ágiles, despiertos, casi felinos, eficientes (Revista Estadio, 1962,1110 , p. 25).
}

territarios 34 148 
El caso de Juan Olivares es bastante ilustrativo y ejemplificador para entender cómo se ha construido el imaginario wanderino. No solo se advierten las diferencias de las características de los estilos, si no que son asimilados y subsumidos a las imágenes urbanas de ambas urbes ${ }^{6}$, e incluso se crean estereotipos en base a cómo están siendo pensadas las disposiciones y particularidades corporales de los habitantes y jugadores de un club y otro. Lo interesante de este caso, así como también podría ser el caso de Jorge Ormeño y Moisés Villarroel (también viñamarinos), es que el ejercicio de recorte y selección con el que operan las construcciones de las imágenes urbanas deja fuera de lo que se entiende como Viña del Mar a sus cerros. Viña es playa, jardines, casino, ocio y modernización constante. Por lo tanto, no es solo el barrio obrero de Santa Inés, el cual queda excluido de la imagen urbana de la ciudad, sino que es toda la época del auge industrial de Viña y el poblamiento de los sectores populares como Achupallas, Nueva Aurora o Santa Inés desde la década de 1930 en adelante (Castagneto, 2010), que quedan excluidos de la selección de la imagen urbana de Viña del Mar. Por lo mismo, la vinculación de Juan Olivares (figura 1) con lo porteño es rápida, simple y directa: Santa Inés se ubica en un cerro, es un barrio predominantemente de trabajadores obreros, de casas elaboradas con base en la autoconstrucción y de vecinos representados por el esfuerzo cotidiano que deben realizar para subsistir económicamente (Santibáñez, 2000).
Figura 1. Juan Olivares, arquero de Santiago Wanderers

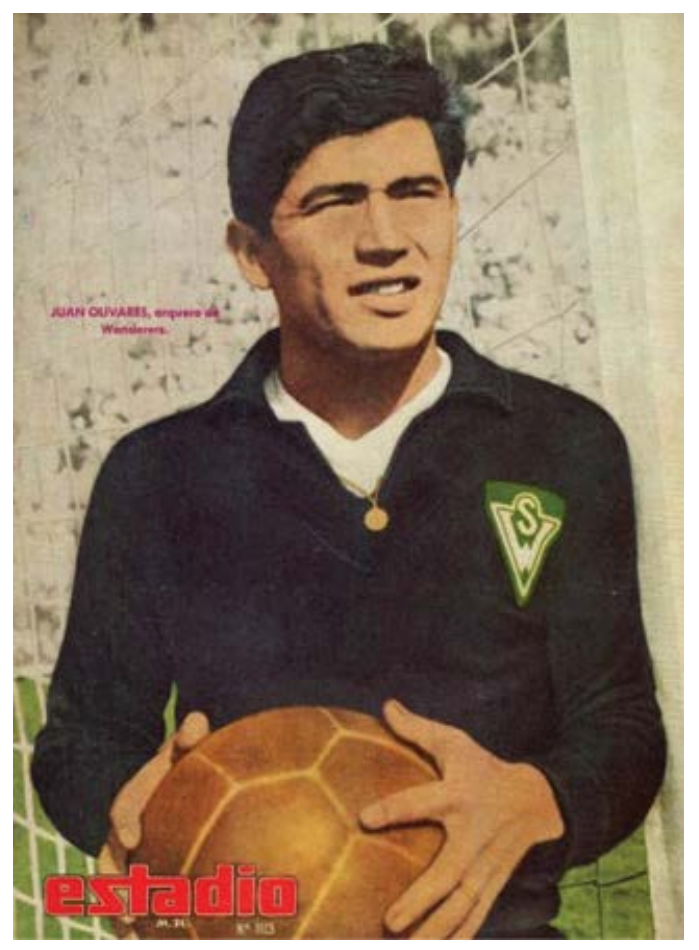

Fuente: Revista Estadio, 1113, 1964.

Entendiendo que los imaginarios urbanos residen en determinados espacios cualificando lugares (Lindón, 2007b; Raffestin, 1986), Santa Inés no logra contener el imaginario viñamarino, sino que posee representaciones y características mucho más asociadas con el universo simbólico porteño. De hecho, cuando nuestros informantes nombran la procedencia de Juan Olivares indican Santa Inés y no Viña del Mar. Algo similar señalan al momento de caracterizar a uno de los actuales integrantes del plantel wanderino, José Lafrentz.
${ }^{6}$ Para indagar en la imagen urbana de Viña del Mar signada por el balneario, el ocio y la "alta sociedad" se sugieve revisar Booth (2003), Ejsmentewi$c z$ (2003) y Urbina (2003). Por otro lado, para interiorizarse en la relación entre imágenes urbanase imaginario se sugiere la revisión de Lacarrieu (2007).

territarias 34 149 
7 Gracias a una investigación realizada por Carlos Aguirre y Valentina Leal (2012) sobre la vida laboral de los estibadores, cabe añadir algunas especificidades: su predominancia como figura pública en la vida urbana porteña de Valparaiso se ubica temporalmente entre la década de 1910 (se debe recordar que entre $1912 y$ 1930 se construye el puerto moderno) y la década de 1980 (debido a la descomposición de la emporchi y la modernización portuaria); fueron caracterizados como "choros", machos, fornidos, mujeriegos, machistas y galantes; tuvieron una relación cercana con la muerte a causa de la cantidad de accidentes experimentados. Esto los llevó a vivir la vida de otro modo, aceptando su transitoriedad y fugacidad. Por los motivos anteriores, se relacionó al estibador con la idea de un vividor, celebrador de la vida, apegado a lo presente pese a su esforzado trabajo.

${ }^{8}$ José Pérez, como jugador de fútbol, defendió las camisetas de Platense, San Lorenzo, Racing Club de France Football y Ferrocarril Oeste. Llegó a Chile en 1948 para hacerse cargo de Badmington como director técnico. Su arribo a Valparaiso se produce un año más tarde, en 1949, para dirigir

territarias 34
El arquero, hijo del actual presidente del club, es resistido por gran parte de los simpatizantes de Santiago Wanderers debido a la seguidilla de errores que se le atribuyen durante partidos que el club porteño perdió en el campeonato clausura 2014. Varias fuentes señalaron que "no es para Wanderers, porque tiene pinta de jugador de Everton", declaraciones totalmente decidoras puesto que actualizan tipificaciones realizadas por Estadio hace más de cuatro décadas, lo que demuestra la forma en la que son representados los viñamarinos y cómo una determinada fisonomía corporal y procedencia socioeconómica no logra hacer sintonía inmediata con lo wanderino y lo porteño. Esta distinción establece límites imaginarios por medio de los estereotipos construidos sobre jugadores wanderinos y evertonianos. Es una suerte de 'rito de institución' (Bourdieu, 2001) puesto que se establecen fronteras ficticias que clasifican a un jugador y a otro. Juan Olivares es viñamarino, pero según Estadio su fisonomía es porteña porque no tiene pelo de tonalidad rubia, ni es elegante como el arquero viñamarino. De hecho, y de acuerdo con el estudio de Aguirre y Leal (2012), su fisonomía es análoga a la de los estibadores del puerto de Valparaíso: moreno, fuerte y "choro"7.

\section{Arrolladores como un tanque: la construcción del estilo de juego wanderino}

En la construcción del estilo de juego wanderino convergen factores de diverso orden.
En primer lugar, aparece la influencia de un director técnico, luego el conocimiento, la adaptación y las condicionantes que posibilitan la geografía física de Valparaíso, y, finalmente, la mediación de Estadio. Los primeros treinta años de vida profesional de Santiago Wanderers estuvieron marcados por una persona en específico: el argentino José 'el gallego' Pérez, nacido en Villa Soldati, en el sur obrero de Buenos Aires ${ }^{8}$. El sello distintivo del director técnico argentino se encuentra en su reconocimiento de la geografía porteña, donde el énfasis estuvo en la política de captación de jugadores en los cerros de Valparaíso y la adaptación del juego al viento característico de Playa Ancha, el cerro donde Wanderers ejerce su localía.

Es relevante mencionar que en el documental A Valparaíso de 1963 del holandés Joris Ivens es posible apreciar variados aspectos de la cotidianidad porteña de aquella época: el trabajo de los estibadores, subir y bajar los cerros por escaleras, el uso del ascensor y la predominantemente persistencia de insatisfacción de necesidades básicas de la gente que residía en los cerros. El técnico argentino José Pérez realizó un trabajo de captación de jugadores provenientes de clubes amateurs localizados en los cerros de la ciudad. Esta forma de trabajo es relatada por exintegrantes del club porteño. En el documental El Wanderers de Valparaiso de Patricio Muñoz, jugadores dirigidos por 'el gallego' Pérez, como Armando Tobar o Juan Olivares, señalan que esta política de captación buscaba identificar al club con jugadores que vivieran en la ciudad. 
O dicho en otras palabras, jugadores que en sus prácticas cotidianas subieran y bajaran escaleras, jugaran en canchas de tierra desniveladas, producto de las características topográficas de la ciudad, o identificaran al estibador como un referente del mundo laboral porteño, es decir, que fueran parte de las prácticas y la ritualidad urbana de Valparaíso9. Al respecto, De Certeau (2000) ha señalado que las prácticas cotidianas permiten la construcción de un sentido del espacio, donde se cruzan los sentimientos acumulados, la memoria y las experiencias corporales.

La figura 2 pretende ilustrar el poblamiento de Valparaíso hacia sus cerros, o colinas. Pero además, resulta interesante, por lo menos, por tres motivos: porque homologa al cerro con la favela brasilera, dada la concentración de población de menores recursos económicos; porque la $S$ que finaliza la palabra favelas se "completa" con una $W$ (S.W. son las iniciales de Santiago Wanderers), dando a entender que el cerro es un territorio wanderino; y porque permite apreciar, tanto en la lejanía como en la cercanía desde dónde se capturó, que el poblamiento se ha producido cerro abajo, ocupando las laderas y conectándose con escaleras que llevan hacia mesetas o zonas planas. La imagen fue capturada en una zona que está, aproximadamente, a doscientos metros sobre el nivel del mar, por lo tanto está inserta en 'el cerro', lugar donde se territorializa la representación de esfuerzo de los y las habitantes de la ciudad.

El cerro, entendido como unidad paisajística de Valparaíso, cobra relevancia por varios motivos; la mayor parte de la población pernocta en esta zona de la ciudad; en los cerros reside una porción importante del imaginario porteño, en tanto la vida

Figura 2. Welcome to "las favelas". Cerro Los Placeres, Escala Mireya

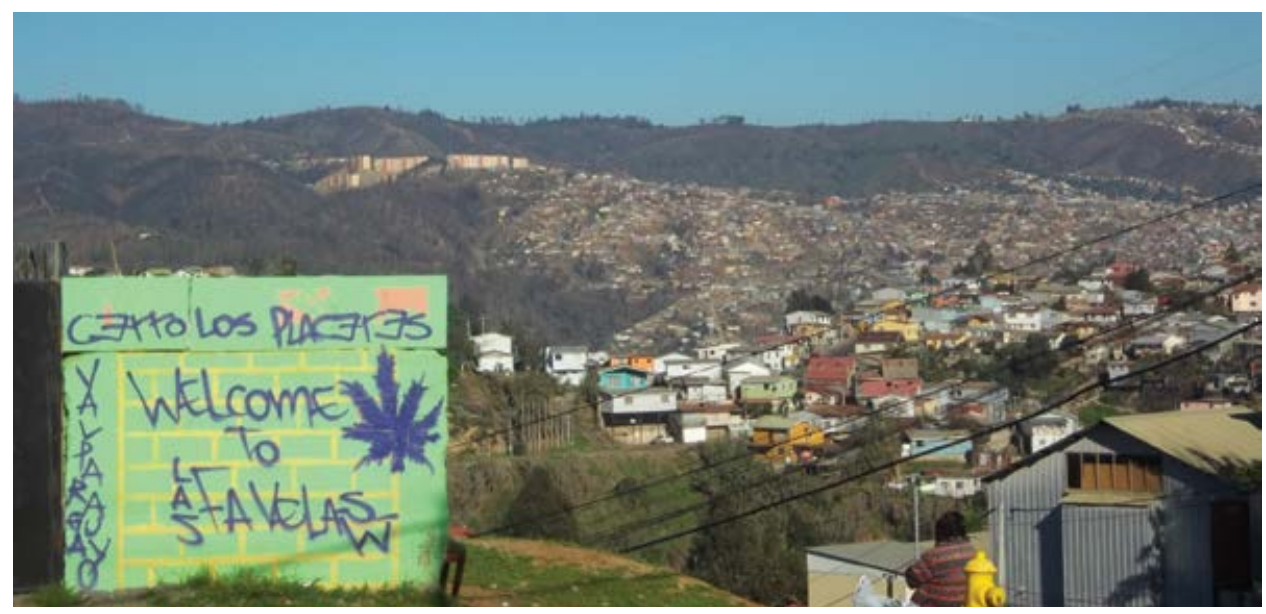

Fuente: fotografía tomada por Carlos Vergara.

Aguerridos, ESFORZAdOS Y PORTEÑOS: EL IMAGINARIO WANDERINO DE VALPARAÍSO

territarias 34

técnicamente a Santiago Wanderers. Sin embargo, el idilio con la ciudad comenzaria en su segundo periodo como d.t. (1956-1961) y se cristalizaría para la posteridad durante su tercer ciclo en 1968. En susperiodos como técnico la institución porteña no sologanaría dos campeonatos de primera división (1958 y 1968) y dos Copa Chile (1959 y 1961), sino que también densificaría su caudal simbólico, acumulando representaciones y fortaleciendo su vínculo con la ciudad.

${ }^{9}$ La investigación sobre la bistoria del Fútbol Amateur en el Cerro Los Placeres de Valparaíso (Romero, 2014) da cuenta de cómo los habitantes ligados a clubes deportivos trabajaban arduamente para nivelar canchas por medio de diferentes medios y estrategias.

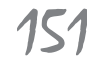


efectuada en esa parte de la ciudad está representada en base al esfuerzo y sacrificio de sus habitantes (Pino \& Ojeda, 2013). Esto se conecta directamente con las ideas de Cosgrove $(1984,2003)$ sobre el paisaje, en tanto este se articula como la unión de una imagen visual y del mundo material, siendo un modo de simbolizarlo y de representarse en tanto se habita inserto en él. Al respecto, Alicia Lindón (2009) ha señalado que el paisaje es totalmente indisociable del cuerpo que lo ve y lo siente. Es más, el paisaje puede ser considerado como un espacio deseado, recordado, imaginado, e incluso somatizado, y que adopta una perspectiva de un sujeto espacialmente concebido, en tanto cuerpo y sentimiento. En otras palabras, los sujetos se presentan dentro de diversos escenarios urbanos —el paisaje, uno de ellos-, donde ponen en juego sus prácticas y apropiaciones del espacio. "Allí en los cerros, subiendo y bajando a la carrera, aspirando sal y yodo, enrojeciéndose al sol de las pichangas interminables se hizo fuerte y duro como las rocas" (sobre Carlos Hoffens) (Revista Estadio, 1963, 1023, p. 41).

Por lo tanto, la política de captación de jugadores establecida por 'el gallego' Pérez, sin lugar a dudas, buscaba recuperar aquello más distintivo del habitante porteño. Pretendiendo que el jugador tuviese un mayor vínculo con la institución y la ciudad, los jugadores idóneos para jugar en Wanderers eran aquellos que, metafóricamente hablando, portaran la ciudad en su cuerpo. Entonces, más allá de que no exista una técnica institucionalizada de inscripción del territorio en el cuerpo, como han ejemplificado Appadurai (1995), para el caso de la circuncisión en los judíos, o Archetti (2008), sobre el imaginario argentino territorializado en el 'potrero', la política de José Pérez pretendía encontrar jugadores que en el día a día, es decir en su ritualidad urbana, tuviesen incorporadas las trayectorias cotidianas de la ciudad: transitar por escaleras, subir-bajar, jugar en canchas desniveladas, etc., pero no solo eso, sino que también tuviesen impregnado un sentimiento vinculante con la ciudad y el habitar en ella. En la figura 3, donde se muestra una obra de Sergio Larraín, reconocido fotógrafo chileno, se expone un escenario urbano común y cotidiano de Valparaíso: la escalera. Resulta relevante comprender que la escalera es un conector entre la zona plana y las colinas (cerros), insoslayable dentro de la ritualidad urbana de la ciudad. El desnivel, o como ha señalado Alejo Carpentier (1967), "la verticalidad de Valparaíso" impone un "esfuerzo adicional", un "sacrificio" y un enfrentamiento a la adversidad para sus habitantes. En definitiva, jugadores con sentido de apropiación sobre el espacio habitado.

Por otro lado, aparece el viento característico de Valparaíso. En el ya citado documental de Joris Ivens fue considerado como uno de los cuatro elementos característicos de la ciudad. Ahora bien, sin la intención de interiorizarnos en la geografía física de la ciudad, quien ha tenido la posibilidad de observar y transitar por distintos cerros de la ciudad, podrá corroborar que Playa Ancha es el cerro donde el viento 
Figura 3. Pasajes y escaleras de Valparaíso, de Sergio Larraín, 1959

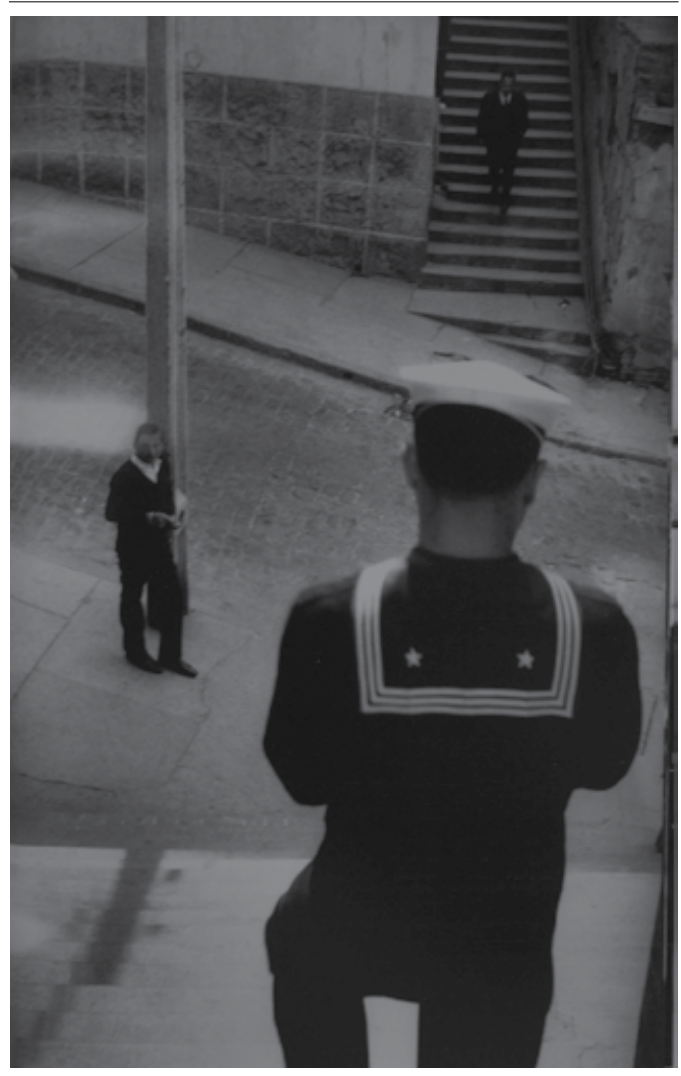

Fuente: Leiva (2012).

aparece cada tarde con una fuerza que no se advierte en otras zonas de la ciudad ${ }^{10}$. Esta característica fue leída y aprovechada por el director técnico argentino. Los relatos del fallecido Oscar Jorge Dubost (1929-2007), jugador de Wanderers por más de quince años, y de Juan Olivares, ejemplifican esta apropiación de las características geográficas por parte de los jugadores:
Nosotros aprendimos a entrenar con el clima de Playa Ancha. A veces lloviendo torrencialmente, estábamos entrenando en el Alejo Barrios. Chapoteando el barro ahí, tirándonos al suelo. Aprendimos a explotar el viento. Nosotros jugábamos mejor en contra del viento, que a favor (Oscar Dubost, 2001).

Sabíamos jugar con el viento. En contra del viento sabíamos que teníamos que jugar a ras de piso, con la pelota lenta, para no perder el balón. $Y$ a favor del viento, la pelota al pie y en forma rápida para sorprender al rival y rematando de todos las distancia (Juan Olivares, 2001).

Ahora bien, las representaciones que ha realizado Estadio sobre los estilos de juego de Wanderers y Everton no siempre tienden a generar oposiciones binarias como comúnmente se piensa. El buen toque, lo agradable, la serenidad, lo galano o el ritmo plácido en ningún caso se entienden como antónimos de lo sólido, el vigor, el espíritu de lucha y el esfuerzo. Wanderers no se caracteriza por tener mal toque o un juego desagradable a la vista. Everton tampoco es un equipo frágil, endeble o poco esforzado. Solamente constituyen tipificaciones para entender cómo expresa cada equipo una forma característica y predominante de jugar al fútbol. Por lo tanto, el punto de interés en el rol instituyente de revista Estadio para la construcción del imaginario wanderino, también en el caso de un hipotético imaginario evertoniano, radica en la relación causal entre territorio y estilo. En el caso del clásico porteño, la rivalidad Wanderers versus Everton es
${ }^{10}$ El viento es un elemento constantemente relevado como característica de Valparaíso. Por ejemplo, en la canción "Valparaiso" de Osvaldo 'gitano' Rodriguez, el viento sur nos falta si no lo tenemos, e incluso es quien "limpia la cara de este puerto herido". 
expresada como una rivalidad entre estilos de territorios pensados en base a la dicotomía ocio/trabajo.

Se nos ocurre que las raíces de uno y otro tienen mucho que ver en la personalidad de estos equipos. Al balneario se va a descansar, a entretenerse, a lucirse, a mirar el mar y los buques. A lucirse ante las niñas tostadas que tienen abiertos los oídos al requiebro. Y Everton es del balneario. En el puerto se camina de prisa, se trabaja, se lucha. Y Wanderers es del puerto (Revista Estadio, 1964, 1133, p. 56).

La cita anterior pertenece al año 1964. Pero en números anteriores, como por ejemplo el 266 de 1949 o el 421 de 1952, Estadio ya elaboraba una relación que subsumía los estilos de juego a las imágenes urbanas de estos territorios que los cobijaban bajo las frases "Wanderers es Valparaíso" y "Everton es Viña del Mar". El discurso periodístico de Estadio asimila que los estilos proceden de las prácticas predominantes que se realizan en una y otra comuna. $E s^{-}$ tadio, editada en Santiago, introyecta una visión capitalina, sobre las representaciones, imágenes y prácticas predominantes en Valparaíso y Viña del Mar. Por lo tanto, en la relación aparentemente causal entre territorio y estilo, Estadio asimiló una imagen urbana para Viña del Mar y Valparaíso, que es asumida como factor causal del estilo de cada uno de los equipos. Sin embargo, la tipificación realizada sobre Wanderers necesariamente oculta que durante el siglo xx en Valparaíso persistió una elite "ociosa"
(Urbina, 2002) y el crecimiento urbano e industrial de determinadas zonas de Viña del Mar necesariamente atrajeron mano de obra, construyéndose algunos emblemáticos barrios obreros, como, por ejemplo, Santa Inés (Castagneto, 2010; Urbina, 2003).

En el documental El Wanderers de Valparaiso, el periodista Edgardo Marín (excronista de revista Estadio y actual periodista de Radio Cooperativa) define el estilo de los equipos wanderinos de los años sesenta y setenta como fuertes, seguros y arrolladores. En una época donde los clubes como la Universidad de Chile y la Universidad Católica marcaban pauta en el fútbol chileno, Santiago Wanderers no se quedaba atrás y lograba hacerle frente a los equipos "grandes" de la capital. A estas alturas, el estadio de Playa Ancha se había convertido en un reducto prácticamente inexpugnable para los equipos que lo visitaban, siendo el aprovechamiento de la localía, por medio del conocimiento, los avatares geográficos - sobre todo el viento-, el gran bastión de las buenas campañas del club porteño. Si bien, los equipos campeones de 1958 (torneo nacional), 1959 y 1961 (Copa Chile), y los subcampeonatos del torneo nacional logrados en 1949, 1956 y 1960 daban cuenta de un estilo asimilado y un club que se mantenía peleando posiciones de avanzada, el segundo campeonato profesional obtenido en 1968 con el tiempo pasó a cobrar ribetes míticos, puesto que pasaron treinta y tres años hasta la consecución de un nuevo campeonato de primera división en 2001 (figura 4). 


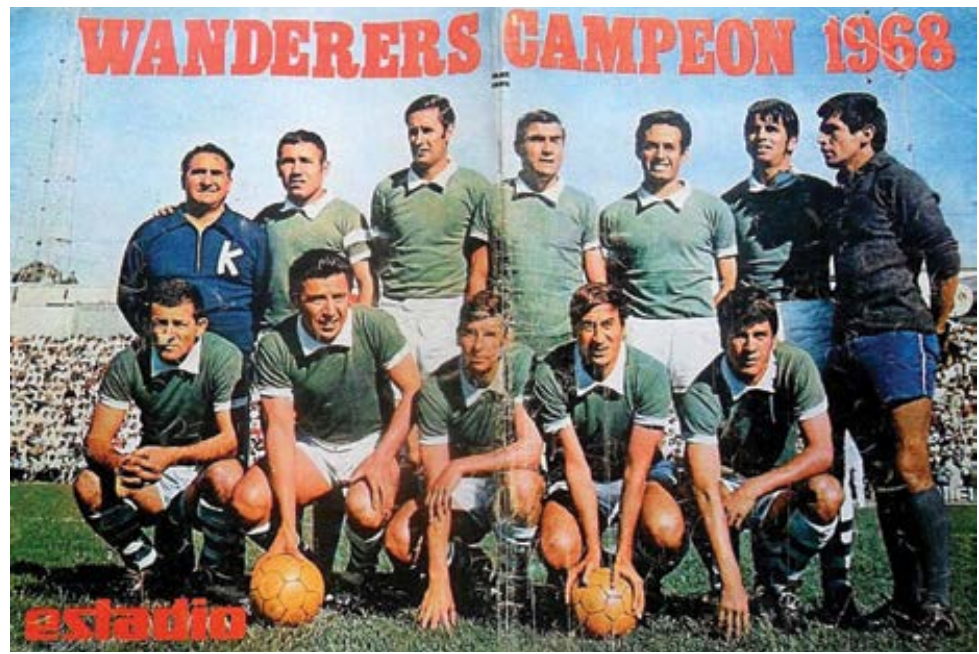

Fuente: Caturrock (2014)

Los panzers - el equipo campeón de 1968 - , pasaría a la historia por varios motivos: un estilo de juego totalmente definido, ser el único equipo de "provincia" capaz de hacerle mella a la hegemonía de los "tres grandes" de Santiago" durante la década del sesenta y lograr el último campeonato durante un periodo de más de treinta años para la institución porteña. Estos motivos condensarían el estilo de juego de Wanderers para la posteridad, puesto que para ser un equipo fuerte, seguro y arrollador se necesitan jugadores que puedan plasmarlo en el campo de juego: Juan Olivares, Vicente Cantatore, Elvio Porcel de Peralta, Mario Griguol, Raúl Toro, Carlos Hoffman entre otros, cumplían a cabalidad las características necesarias para plasmar el estilo. Revista Estadio señaló que eran trabajadores, fuertes y valientes, todos condimentos necesarios para jugar en un equipo de Valparaíso y ser un equipo arrollador que pudiese hacer valer la analogía con el tanque alemán utilizado en la segunda guerra mundial. Pero es más, el equipo de los panzers tiende a culminar dos décadas de satisfacciones para los habitantes de Valparaíso, realizando una síntesis sobre representaciones culturales y espaciales de la ciudad. A saber: la disposición corporal del porteño (fortaleza física), la forma en la que es representada su cotidianeidad (esfuerzo) y las características geográficas de la ciudad (viento). En definitiva, el estilo de juego wanderino condensa prácticas cotidianas del habitar en Valparaíso, características geográficas propias del emplazamiento de la ciudad y representaciones, en clave normativa, a cerca de lo porteño y lo wanderino.
11 Desde la década de los ochenta en adelante, los medios de comunicación masivos nacionales de Chile (prensa, televisión y periódicos), ban denominado como "lostresgrandes" a los equipos más ganadores de la capital de Chile: Colo Colo, Universidad de Chile y Universidad Católica. 


\section{Reflexiones finales}

Durante la época de vigencia de revista $E s^{-}$ tadio, el imaginario wanderino fue actualizado y llenado de representaciones que circulan por un canal con llegada nacional. En ese sentido, por medio de Estadio, Wanderers y Valparaíso pueden ser conocidos e imaginados por un público más amplio. El registro de esta revista es relevante porque los reporteros toman nota de lo que ven, lo que oyen, etc., y en sus crónicas es posible apreciar una suerte de síntesis entre sus esquemas de percepción ya construidos sobre Valparaíso y los aspectos que emergen a propósito de su trabajo periodístico en este territorio (notas, entrevistas, conversaciones, etc.).

Resulta interesante la vinculación entre la construcción discursiva de Valparaíso (de la que se habló en la introducción del texto) y la trama de significados que emergen a propósito de las representaciones que recaen sobre los habitantes, vistos en la Revista Estadio. En este sentido, el símbolo wanderino logra organizar y visibilizar la trama de la cultura urbana de Valparaíso, puesto que otorga una construcción de sentido que enlaza lugares (el espacio portuario, la ciudad de Valparaíso y una de sus unidades geográficas: el cerro), con prácticas (la significación sobre cómo, normativamente, se debe jugar al fútbol en Valparaíso y la forma como enfrentarse a la adversidad geográfica del cerro), y con sujetos (precisamente el ídolo y el habitante "corriente" que debe demostrar una disposición para residir en un "lugar inhóspito").
Entonces, si bien el imaginario wanderino nace a propósito de la fundación del club y también tiene desarrollo en una fase previa a Estadio, el trabajo de esta revista le ha otorgado referencias sólidas sobre lo porteño y lo wanderino, ocupando muchas veces como "espejo" a la vecina Viña del Mar y su club Everton. Estas han sido confirmadas mediante registros orales $\mathrm{y} / \mathrm{o}$ videográficos de habitantes de Valparaíso, cobrando mucho sentido lo señalado por Archetti (2001), puesto que "el fútbol ayuda a construir la imagen de 'uno' a partir de las diferencias con el 'otro' o los 'otros' masculinos en plural” (p. 425).

La presencia simbólica de Santiago Wanderers a lo largo y alto de la ciudad (por medio murales y rayados) dan cuenta de su carácter patrimonial, popular y masivo, lo que la constituye como una de las expresiones culturales que más identifican a Valparaíso (figura 5).

A propósito de este trabajo, y hablando en materia de los Estudios Sociales del Fútbol, resulta fundamental la ayuda que puede proporcionar el cuerpo teórico de la geografía humana. En este caso, la mezcla de elementos como el viento, la disposición topográfica de un territorio y las disposiciones mentales y corporales de los habitantes de Valparaíso hna construido un estilo de juego donde existe una forma de jugar cristalizada hace más de cuarenta años. En este sentido, no sería incorrecto proponer una suerte de geografía de los estilos de juego en Chile y Sudamérica. Aquello podría proporcionar referencias geográficas para indagar aspectos simbólicos de las urbes 


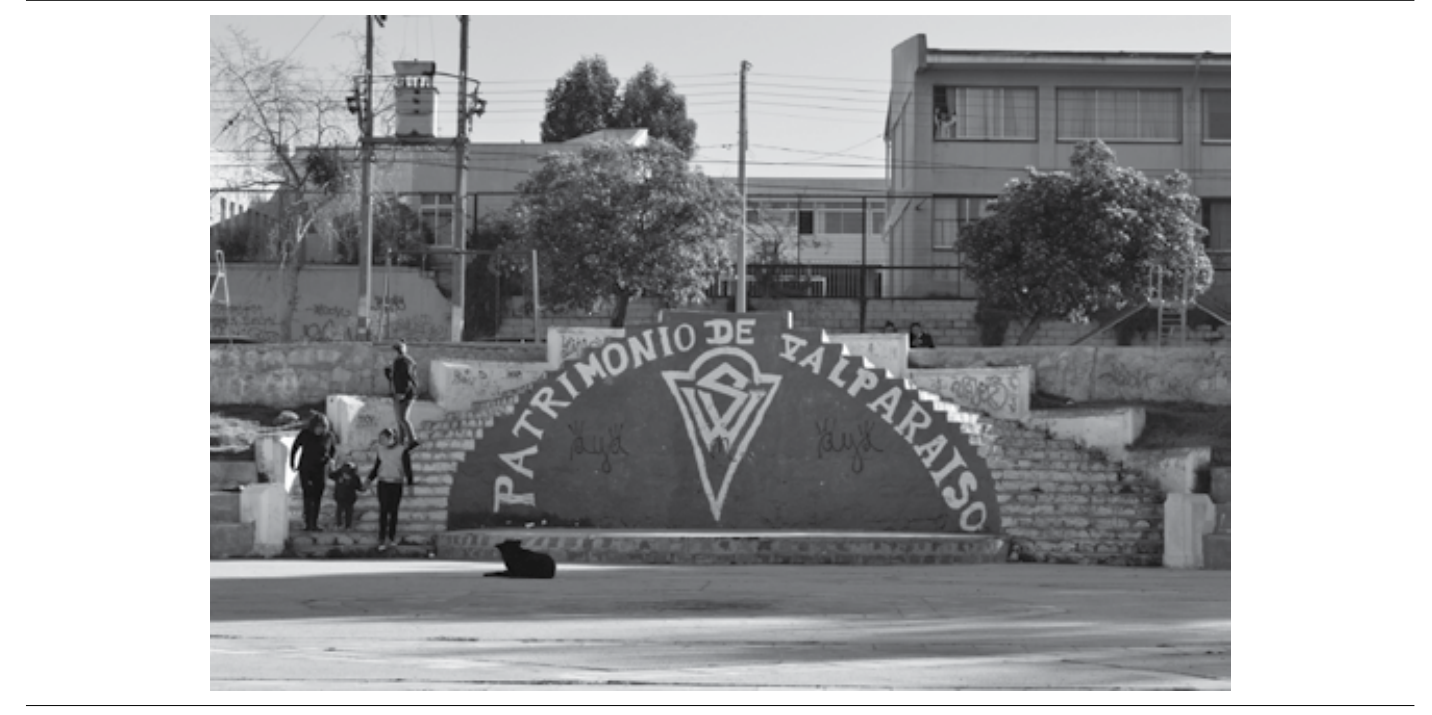

Fuente: fotografía tomada por Sebastián Ponce.

donde el fútbol tiene presencia destacada, puesto que el estilo de juego se superpone a los vaivenes deportivos de un club o una nación determinada. De acuerdo con lo anterior, es totalmente posible imaginar una victoria so pena de traicionar el estilo de juego, así como una derrota, confirmando y respetando un modo de jugar (Archetti, 2001). Por ejemplo, desde la década de 1970 adelante el fútbol profesional cambió en el mundo, los equipos cada vez tienen menos jugadores locales, se han creado figuras legales que posibilitan la intromisión de grandes capitales y el mundo privado en la administración de los clubes y la mayor difusión del fútbol europeo supone un nuevo parámetro que deja al fútbol local en una posición subordinada (Valenzuela \& Vergara, 2014). En esta época, Wanderers descendió por primera (y no única) vez, en sus filas hay mayor presencia de jugadores que no nacieron y nunca han residido en Valparaíso; desde la segunda mitad de la década de los noventa su lugar de entrenamiento deja de estar en Playa Ancha, y durante los últimos cinco años se modifica la administración del club en el marco de la ley de sociedades anónimas deportivas, siendo entregada la concesión del club a empresarios ligados al mundo del retail.

El imaginario wanderino actualmente ha adquirido formas resistentes y patrimoniales que serán revisadas en otras oportunidades, pero, a pesar de aquello, persiste un estilo que, siendo parte de matrices de sentido de quienes habitan Valparaíso, dice que los wanderinos deben ser aguerridos, fuertes, choros, etc., y que eso debe ser 
plasmado en el campo de juego, porque los equipos son representativos de... En ese sentido, el estilo se posiciona preferentemente en el plano evocativo, pero no por aquello menos real e influyente en el pensamiento de quienes pertenecen a la comunidad wanderina y porteña.

\section{Referencias}

Aguirre, C., \& Leal, V. (2012). Estiba y desestiba. Trabajo y relatos de un Valparaiso que fue (1938-1981). Valparaíso: CNCA.

Alabarces, P. (2000). Los estudios sobre deporte y sociedad: objetos, miradas, agendas. En P. Alabarces, (Ed.), Peligro de Gol (pp.11-32). Buenos Aires: CLACSO.

Alabarces, P. (2007). Fútbol y patria. Buenos Aires: Prometeo Libros.

Appadurai, A. (1995). The production of locality. En R. Fardon (Ed.), Counterworks: managing the diversity of knowledge (pp. 208-229). London: Routledge.

Archetti, E. (2001). Estilo y virtudes masculinas en El Gráfico: la creación del imaginario del fútbol argentino. Desarrollo Económico, 35(19), 419-442.

Archetti, E. (2008). El potrero y el pibe. Territorio y pertenencia en el imaginario del fútbol argentino. Horizontes Antropológicos, 14(30), 259-282.

Backzo, B. (1991). Los imaginarios sociales. Memorias y esperanzas colectivas. Buenos Aires: Nueva Visión.

territarias 34

Bailly, A. (1989). Lo imaginario espacial y la geografía: en defensa de la geografía de las representaciones. Anales de Geografía 8(9), 11-19.

Berger, P., \& Luckmann, T. (2000). La construcción social de la realidad. Buenos Aires: Amorrortu.

Booth, R. (2003). Ocio y Arquitectura en la conformación de la imagen urbana viñamarina. Revista ARCHIVUM, IV(5), 139-162.

Bourdieu, P. (2001). Los ritos de institución. En P. Bourdieu, ¿Qué significa hablar? (pp. 78-86). Madrid: Akal Ediciones.

Calderón, A., \& Schlotfeldt, M. (2001). Memorial de Valparaiso. Santiago: Ril Editores.

Carpentier, A. (2001). Tientos y diferencias. En A. Calderón \& M. Schlotfeldt, $M e^{-}$ morial de Valparaíso (pp. 437-438). Santiago: Ril Editores.

Castagneto, P. (2010). Una historia de Viña del Mar. Santiago: RIL Editores.

Caturrock (2014). De la mano de "Los Panzers" Santiago Wanderers logró su segunda estrella. Recuperado de: http:// www.eseaene.cl/sitio/05/01/2014/ de-la-mano-de-los-panzers-santiagowanderers-logro-su-segunda-estrella

Cosgrove, D. (1984). Social formation and symbolic landscape. Beckenham-Kent: Croom Helm.

Cosgrove, D. (2003). Apollo's Eye: A cartographic Genealogy of the Earth in the Western Imagination. Baltimore: John Hopkins University Press.

Dávila, A., \& Londoño, C. (2003). La nación bajo un uniforme: fútbol e identidad nacional en Colombia 1985-2000. En 
P. Alabarces (Ed.), Futbologias (pp.123143). Buenos Aires: Clacso.

De Certeau, M. (2000). La invención de lo cotidiano I. Artes de hacer. México D.F.: Universidad Iberoamericana.

Di Meo, G. (1999). Géographies tranquilles du quotidien: une analyse de la contribution des sciences sociales et de la géographie à l'étude des pratiques spatiales. Cabiers de géographie du Québec, 43(118), 75-93.

Díaz, M. (1952). Santiago Wanderers, Biografía anecdótica de un club. Valparaíso: Ediciones Stadium.

Ejsmentewicz, A. (2003). Viña del Mar ¿̨ocio o negocio? Revista ARCHIVUM, IV (5), 139-162.

Fuentes-Gómez, J. (2000). Imágenes e imaginarios urbanos: su utilización en los estudios de las ciudades. Ciudades, 6(46), 3-10.

García Canclini, N. (1997). Imaginarios Urbanos. Buenos Aires: Editorial Universitaria.

Guerrero, B. (2006). Fútbol en el norte grande de Chile: identidad nacional e identidad regional. Revista de Ciencias Sociales, 15(16), 4-15.

Hiernaux, D. (2007). Los imaginarios urbanos: de la teoría y los aterrizajes en los estudios urbanos. Revista EURE, XXXIII(99), 17-30.

Lacarrieu, M. (2007). La insoportable levedad de lo urbano. Revista EURE, $\operatorname{XXXIII}(99), 47-64$.

Lindón, A. (2006). Geografías de la vida cotidiana. En: D. Hiernaux \& A. Lindón
(Dirs.), Tratado de Geografía Humana. (pp. 466-536). Barcelona: Anthropos.

Lindón, A. (2007a). Los imaginarios urbanos y el constructivismo geográfico: los hologramas espaciales. Revista EURE, $\operatorname{XxXIII}(99), 31-46$.

Lindón, A. (2007b). La ciudad y la vida urbana a través de los imaginarios. Revista EURE, XXXIII(99), 7-16.

Leiva, G. (2012). Sergio Larrain. Biografia/ Estética/Fotos. Santiago: Ediciones Metales Pesados.

Ley, D. (1978). Social geography and social action. En D. Ley \& M. Samuels (Eds.), Humanistic geography: prospects and problems. (pp. 41-57). London: Croom-Helm.

Longo, M. (2006). Narración y sociología. Literatura, sentido común, escritura sociológica. Revista crítica de Ciencias Sociales y Jurídicas - Nómadas, 8(14), $1-18$.

Marín, E. (1995). Centenario. Historia total del fútbol chileno: 1895-1995. Santiago: Editores y Consultores REI.

Márquez, F. (2007). Imaginarios urbanos en el Gran Santiago: huellas de una metamorfosis. Revista EURE, XXXIII(99), 79-88.

Melgar, R. (2001). El universo simbólico en el pensamiento de Víctor Turner. Revista Investigaciones Sociales, 5(7), 7-21.

Muñoz, P. (2001). El Wanderers de Valparaíso (documental). Recuperado de: https://www.youtube.com/watch? $\mathrm{v}=\mathrm{ueLEosn} 6 \mathrm{zOc}$

Ossandón, C., \& Santa Cruz, E. (2001). Entre las alas y el plomo: la gestación de 
la prensa moderna en Chile. Santiago: Ediciones LOM-ARCIS-DIBAM.

Pino, A., \& Ojeda, L. (2013). Ciudad y hábitat informal: las tomas de terreno y la autoconstrucción en las quebradas de Valparaíso. Revista INVI, 28(78), 109142.

Pinto, J. (1987). Valparaíso metrópolis financiera del boom del salitre. En S. Lorenzo, (Comp.), Valparaiso, 1536-1986. Primera jornada de Historia Urbana (pp. 119-150). Valparaíso: Instituto de Historia - Pontificia Universidad Católica de Valparaíso.

Raffestin, C. (1986). Ecogénése territoriale et territorialité. En E. Auriac \& R. Brunet, (Dirs.), Espaces, jeux et enjeux (pp. 175-185). París: Fayard.

Revista Estadio (1958). 815, 14-15

Revista Estadio (1962). 1110, 25

Revista Estadio (1963). 1023, 41

Revista Estadio (1964). 1133, 56

Romero, M. (2014). Goles y fútbol en tierras del Cerro Los Placeres. Historias de familias y poblaciones. Valparaíso: CNCA.

Santa Cruz, E. (1991). Crónica de un encuentro: fútbol y cultura popular. Santiago: Ediciones Instituto ARCOS.

Santa Cruz, E. (1996). Origen y futuro de una pasión (Fútbol, cultura y modernidad). Santiago: Ediciones LOM.

Santa Cruz, E. (2003). Fútbol y nacionalismo de mercado en el Chile actual. En P. Alabarces, (Ed.), Futbologías (pp. 199224). Buenos Aires: Clacso.

Santa Cruz, E. (2012). Prensa, espacio público y modernización: las revistas deporti- vas en Chile (1900-1950). Recorde: Revista do História do Esporte, 5(2), 1-21.

Santa Cruz, E., \& Santa Cruz, L. (2005). Las escuelas de la identidad. La cultura y el deporte en el Chile desarrollista. Santiago: Ediciones LOM - Universidad ARCIS. Santibáñez, H. (2000). La memoria de los barrios. Sintesis de cinco historias locales de Viña del Mar contadas por adultos mayores. Viña del Mar: Taller Ediciones.

Silva, A. (1986). Graffiti: una ciudad imaginada. Bogotá: Tercer Mundo Editores.

Silva, A. (2006). Imaginarios Urbanos. Bogotá: Arango Editores.

Trivelli, P., \& Nishimura, Y. (2010). The sustentability of urban heritage preservation: interventions to supporteconomic and residential investments in urban heritage areas of Latin America and the Caribbean: case study Valparaiso. Santiago: Trivelli y Cía.

Urbina, M. (2002). Los conventillos de Valparaiso 1880-1920. Fisonomía y percepción de una vivienda popular urbana. Valparaíso: Ediciones Universitarias de Valparaíso.

Valles, M. (2000). Técnicas cualitativas de investigación social: reflexión metodológica y práctica profesional. Madrid: Editorial Síntesis.

Victoriano, F., \& Darrigrandi, C. (2009). Representación. En M. Szurmuk \& R. Mckee Irwin, (Coords.), Diccionario de Estudios Culturales Latinoamericanos. (pp. 249-259). México D.F.: Instituto Mora - Siglo XXI Editores. 